\title{
IDENTIFIKASI KANDUNGAN DAUN NGGORANG (Salvia occindentalis Sw) MENGGUNAKAN SPEKTROFOTOMETER GC-MS
}

\author{
Identification Of The West Indian Sage (Salvia occindentalis Sw) Content Using \\ GC-MS Spectrophotometer
}

\author{
Sisilia Teresia Rosmala Dewi*, Djuniasti Karim, Damaris \\ Jurusan Farmasi Politeknik Kesehatan Kemenkes Makassar \\ *Koresponden Email : sildewi0310@yahoo.com
}

DOI: https://doi.org/10.32382/mf.v16i2.1806

\section{ABSTRACT}

Nggorang or west indian sage (Salvia occidentalis $S w$.$) leaffrom Tenda Village, Langke Rembong$ Subdistrict, Manggarai Regency, NTT Province. It is empirically used as an anticancer for breasts, coughs, and nosebleeds, but the leaf compounds needs to be studied. This research aims to identify the content contained in the leaf of west indian sage (Salvia occidentalis Sw) using GC-MS spectrophotometer. The leaves were extracted using the maceration method with methanol extractor, and the contents were analyzed using GC-MS with CP-Sil 5CB as the stationary phase. The results showed that the west indian sage (Salvia occidentalis Sw.) leaf contains: 3, 7, 11, 15-Tetramethyl-2-hexadecen-1-ol [ $\left.\mathrm{C}_{2} \mathrm{OH}_{40} \mathrm{O}\right], \mathrm{n}_{\text {- }}$ Hexadecanoid acid [ $\left.\mathrm{C}_{16} \mathrm{H}_{32} \mathrm{O}_{2}\right]$, 7-Isopropyl-1, 1, 4a-trimethyl-1, 2, 3, 4. 4a ,9, 10a-, octahydrophenantrene

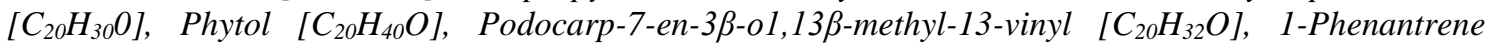

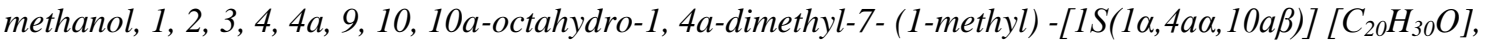
Heptriacotanol [ $\left.\mathrm{C}_{37} \mathrm{H}_{76} \mathrm{O}\right]$ (Alkohol), 9-(2', 2'-Dimethy propanoilhydrazono)-3,6-dichloro-2, 7- bis-[2(diethylamino)-ethoxy] fluorine [ $\mathrm{C}_{30} \mathrm{H}_{42} \mathrm{C}_{12} \mathrm{~N}_{4} \mathrm{O}_{3}$ ], 1- Phenanthrene carboxylic acid, 7-ethenyl-1, 2, 3, 4, 4a, $4 b, 5,6,7,9,10,10 a$-dodecahydro 4a, 7 dimethyl $[1 R(1 \alpha, 4 a \beta, 4 b \alpha, 7 \beta, 10 a \alpha)]\left[C_{19} H_{28} \mathrm{O}_{2}\right], 1,2$-Dihydro11-oxo-prednisolone 11-dehydroxy-9-thiocynato $\left[\mathrm{C}_{22} \mathrm{H}_{27} \mathrm{NO}_{5} \mathrm{~S}\right]$, therefore, it was concluded that west indian sage (Salvia occidentalis Sw.) leaves contain compounds such as Terpenoida, Palmitic Acid, Steroids, Chlorophyll, Vitamin A, Beta Carotene, Alcohol, Phenolic Acid, Testosterone, Prednisolone.

Keywords : Chemical Ingredients, West indian sage (Salvia occidentalis $S w$ ) leaf, GC-MS

\begin{abstract}
ABSTRAK
Daun Nggorang (Salvia occidentalis Sw.) yang berasal dari Desa Tenda Kecamatan Langke Rembong Kabupaten Manggarai Provinsi NTT. Secara empiris digunakan sebagai antikanker payudara, batuk, dan mimisan namun kandungan senyawa di dalam daun ini masih perlu diteliti. Penelitian ini bertujuan untuk mengidentifikasi kandungan yang terdapat pada Daun Nggorang (Salvia occidentalis Sw) secara spektrofotometer GC-MS. Daun Nggorang (Salvia occidentalis Sw.) diekstraksi menggunakan metode maserasi dengan cairan penyari metanol, lalu dianalisis kandungannya menggunakan GC-MS dengan fase diam CP-Sil 5CB. Hasil penelitian menunjukan Daun Nggorang (Salvia occidentalis Sw.) mengandung : 3, 7, 11, 15-Tetramethyl-2-hexadecen-1-ol [ $\left.\mathrm{C}_{2} \mathrm{OH}_{40} \mathrm{O}\right]$, n-Hexadecanoid acid $\left[\mathrm{C}_{16} \mathrm{H}_{32} \mathrm{O}_{2}\right]$, 7-Isopropyl-1, 1, 4a-trimethyl-1, 2, 3, 4. 4a ,9, 10a-, octahydrophenantrene $\left[\mathrm{C}_{20} \mathrm{H}_{30} \mathrm{O}\right]$, Phytol $\left[\mathrm{C}_{20} \mathrm{H}_{40} \mathrm{O}\right]$, Podocarp-7-en-3 $\beta$ o1,13 $\beta$-methyl-13-vinyl [ $\left.\mathrm{C}_{20} \mathrm{H}_{32} \mathrm{O}\right]$, 1-Phenantrene methanol, 1, 2, 3, 4, 4a, 9, 10, 10a-octahydro-1, 4a-

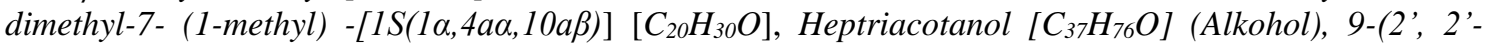
Dimethy propanoilhydrazono)-3,6-dichloro-2, 7- bis-[2-(diethylamino)-ethoxy] fluorine $\left[\mathrm{C}_{30} \mathrm{H}_{42} \mathrm{C}_{12} \mathrm{~N}_{4} \mathrm{O}_{3}\right]$, 1- Phenanthrene carboxylic acid, 7-ethenyl-1, 2, 3, 4, 4a, 4b, 5, 6, 7, 9, 10, 10a-dodecahydro 4a, 7 dimethyl $[1 \mathrm{R}(1 \alpha, 4 a \beta, 4 b \alpha, 7 \beta, 10 a \alpha)]\left[\mathrm{C}_{19} \mathrm{H}_{28} \mathrm{O}_{2}\right], 1,2-D i h y d r o-11$-oxo-prednisolone 11-dehydroxy-9-thiocynato $\left[\mathrm{C}_{22} \mathrm{H}_{27} \mathrm{NO}_{5} \mathrm{~S}\right]$, sehingga dapat disimpulkan Tanaman Daun Nggorang (Salvia occidentalis Sw.) mengandung senyawa Terpenoida, Asam Palmitat, Steroid, Klorofil, Vitamin A, Beta Karoten, Alkohol, Asam Fenolik, Testosteron, Prednisolon.
\end{abstract}

Kata Kunci : Kandungan Kimia, Daun Nggorang (Salvia occidentalis Sw), GC-MS. 


\section{PENDAHULUAN}

Indonesia merupakan negara dengan kekayaan hayati terbesar di dunia yang memiliki lebih 3000 spesies tanaman tinggi. Hingga saat ini, tercatat 7000 spesies tanaman telah diketahui khasiatnya, namun, kurang dari 300 tanaman yang digunakan sebagai bahan industry farmasi secara regular, sekitar 1000 tanaman telah di indentifikasi dari aspek botani sistematika tumbuhan dengan baik (Wati, 2017).

Tanaman obat sudah banyak sekali digunakan oleh manusia sejak zaman dahulu, bahkan dipercaya mempunyai khasiat yang lebh ampuh daripada obat-obat dokter, namun karena perkembangan zaman dan semakin meningkatnya pengetahuannya manusia tentang farmakologi dan ilmu kedokteran, banyak masyarakat yang beralih ke obat-obatan dokter karena lebih mempercayai obat-obatatan kimia yang telah teruji khasiatnya secara laboratorium, dibandingkan dengan obat tradisional yang banyak belum bisa dibuktikan secara ilmiah (Jumar, 2010).

Pengetahuan tentang pemanfaatan tumbuhan obat di Indonesia sekarang itu masih banyak yang belum diketahui dan dieksplorasi oleh masyarakat. Hal ini dibuktikan denagn penulisan tentang jenis tumbuhan obat dan makalah internasional, Indonesia hanya menyumbang karya ilmiah $0,0012 \%$ jauh dengan jepang yang menyumbang $8 \%$, oleh karena itu, tumbuhan obat dan pemanfaatannya perlu diperkenalkan ke masyarakat umum dan dikaji lebih dalam lagi (Wijayakusuma, 2000), salah satunya adalah Tanaman Nggorang

$$
\text { Tanaman Nggorang }
$$

(Salvia occidentalis) salah satu obat tradisional untuk penyembuhan terhadap penyakit yang dilakukan berdasarkan kepercayaan turun-temurun, yang diyakini mempunyai khasiat menyembuhkan penyakit, melalui perantara seseorang (dukun) yang diakui mempunyai kekuatan tertentu di dalam dirinya untuk menghilangkan penyakit. Masyarakat Manggarai masih sangat mempercayai adat istiadat yang tinggi, salah satunya tetap mempertahankan pengobatan tradisional melalui "ata mbeko" (dukun) mulai acara kelahiran, menikah sampai kematian, masyarakat menggunakan bahan alami untuk mengobati segala macam penyakit. Bayi yang baru dilahirkan dukun beranak menggunakan bambu yang telah dibersihkan untuk memotong tali pusar, pusar bayi diobati dengan nggorang yang dikunyah oleh dukun beranak dan disemburkan ke tali pusar. Ibunya direndam dalam air hangat yang ditambahkan daun dan akar nggorang yang berfungsi sebagai obat bila terjadi perdarahan. Acara pernikahan ditandai dengan wedi ruha (injak telur) dan telur diletakkan diatas daun nggorang sebelum pesta pernikahan, dan acara kematian tidak boleh makan sebelum yang meninggal diberi makan dengan daun nggorang (teing hang). Adat istiadat masyarakat ini masih tetap dipertahankan, walaupun pengobatan modern sudah banyak (Dewi STR, 2019)

Namun yang menjadi permasalahan bagi peminat obat tradisional kandungan dari bahan kimia pada tanaman Nggorang, oleh karena itu, peneliti tertarik untuk mengetahui kandungan kimia apa saja yang ada pada Daun Nggorang menggunakan Spektrofotometer GCMS.

\section{METODE}

\section{Jenis Penelitian}

Jenis penelitian ini merupakan penelitian eksplorisasi untuk mengidentifikasi kandungan daun Nggorang (Salvia occidentalis) secara spektrofotometer GC.MC.

\section{Waktu dan Tempat Penelitian}

Penelitian ini dilaksanakan pada bulan Mei - Juni 2019 di Laboratorium Besar Kesehatan Makassar dan di Laboratorium Biologi Farmasi Jurusan Farmasi Poltekkes Kemenkes Makassar.

\section{Alat dan Bahan}

Alat-alat yang digunakan antara lain alat Maserasi, Corong Pisah (Pyrex), Gelas Ukur 10 $\mathrm{ml}$ (Pyrex), Gelas Kimia $500 \mathrm{ml}$ (Pyrex), Timbangan Analitik (JCS-K), Spektrofotometer GC-MS (Thermo Scientific).

Bahan yang digunakan terdiri dari Etanol $\left(\mathrm{C}_{2} \mathrm{H}_{6} \mathrm{O}\right)$, Kertas Saring, Lakban, Metanol $\left(\mathrm{CH}_{4} \mathrm{O}\right)$, Daun Nggorang ( Salvia occidentalis).

\section{Cara Kerja}

\section{Penyiapan dan preparasi sampel}

Sampel yang digunakan berupa Daun Nggorang (Salvia occidentalis $\mathrm{Sw}$ ) yang diambil di Desa Tenda Kecamatan Langke Rembong Kabupaten Manggarai Provinsi NTT, pada jam 06-10 wita. Pemanenan daun dilakukan pada saat proses fotosisntesis maksimal, yang dipetik saat warna pucuk daun berubah menjadi tua mulai daun ke-5 dari pucuk daun. Daun Nggorang dicuci lalu dipotong kecil-kecil, kemudian dikeringkan ditempat yang teduh (terlindung dari cahaya).

Pembuatan Ekstrak Metanol Daun Nggorang

Ekstraksi Daun Nggorang (Salvia occidentalis $\mathrm{Sw}$ ) dengan menggunakan metode maserasi. Simplisia yang telah dipotong-potong kecil sesuai dengan derajat halus (5/8) kemudian ditimbang sebanyak 500 gram lalu di masukkan 
ke dalam wadah maserasi kemudian di tambahkan metanol hingga seluruh simplisia terendam. Wadah maserasi ditutup rapat lalu dibiarkan selama 5 hari dan sekali-kali diaduk, pelarut diganti tiap 5 hari sekali dan penggantian pelarut dilakukan sebanyak 3 kali. Filtrat dan endapan dipisahkan, selanjutnya filtrat diuapkan pada rotavapor dan diidentifikasi.

Identifikasi dengan Spektrofotometer GC-MS

Sampel sebanyak 1gram dimasukkan ke dalam alat destilasi uap yang dilengkapi kondensor, kemudian dipanaskan. Destilat yang diperoleh merupakan campuran minyak dengan Hasil Penelitian

Tabel 1: Hasil Pemeriksaan Identifikasi Kandungan Senyawa Kimia daun Nggorang (Salvia occidental Sw) menggunakan Spektrofotometer GC-MS

\begin{tabular}{|c|c|c|c|}
\hline RT & $\begin{array}{l}\text { Probabilitas } \\
\qquad(\%)\end{array}$ & Senyawa & Zat Kimia \\
\hline 10.55 & 26.70 & $\begin{array}{l}\text { 3,7,11,15-Tetramethyl-2-hexadecen-1-ol } \\
{[\mathrm{C} 20 \mathrm{H} 40 \mathrm{O}]}\end{array}$ & $\begin{array}{l}\text { Terpenoida } \\
\text { (Alia, 2017) }\end{array}$ \\
\hline 11.38 & 71.60 & n-Hexadecanoic acid [C16H32O2] & $\begin{array}{l}\text { Asam Palmitat } \\
\text { (Debora, 2017) }\end{array}$ \\
\hline 12.36 & 91.40 & $\begin{array}{c}\text { 7-Isopropyl-1,1,4a-trimethyl- } \\
\text { 1,2,3,4,4a,9,10,10a- } \\
\text { octahydrophenanthrene } \\
{[\mathrm{C} 20 \mathrm{H} 30]} \\
\end{array}$ & $\begin{array}{c}\text { Steroid } \\
\text { (Lee.K.W, 2012) }\end{array}$ \\
\hline 12.5 & 38.50 & Phytol [ C20H40O] & $\begin{array}{c}\text { Klorofil } \\
\text { (Debora, 2015) }\end{array}$ \\
\hline 14.3 & 17.90 & $\begin{array}{c}\text { Podocarp-7-en-3 } \beta \text {-ol, } 13 \beta \text {-methyl-13- } \\
\text { vinyl- }[\mathrm{C} 20 \mathrm{H} 32 \mathrm{O}]\end{array}$ & $\begin{array}{c}\text { Vitamin A } \\
\text { (Andre P, 2000) }\end{array}$ \\
\hline 14.62 & 86.70 & $\begin{array}{c}\text { 1-Phenanthrenemethanol, } \\
\text { 1,2,3,4,4a,9,10,10a-octahydro-1,4a- } \\
\text { dimethyl-7-(1-methylethyl)-, [1S- } \\
(1 \alpha, 4 \mathrm{a} \alpha, 10 \mathrm{a} \beta)][\mathrm{C} 20 \mathrm{H} 30 \mathrm{O}]\end{array}$ & $\begin{array}{l}\text { Beta Karoten } \\
\text { (Afifah Kurnia, } \\
\text { 2017) }\end{array}$ \\
\hline 14.89 & 26.00 & 1-Heptatriacotanol [C37H76O] & $\begin{array}{c}\text { Alkohol } \\
\text { (Lee,K,W 2003) }\end{array}$ \\
\hline 15.66 & 14.30 & $\begin{array}{c}\text { 9-(2',2'-Dimethylpropanoilhydrazono)- } \\
\text { 3,6-dichloro-2,7-bis-[2-(diethylamino)- } \\
\text { ethoxy]fluorene } \\
\text { [ C30H42Cl2N4O3] }\end{array}$ & $\begin{array}{c}\text { Asam Fenolik } \\
\text { (Tyas Ayu, 2013) }\end{array}$ \\
\hline 15.9 & 28.90 & $\begin{array}{c}\text { 1-Phenanthrenecarboxylic acid, 7-ethenyl- } \\
\text { 1,2,3,4,4a,4b,5,6,7,9,10,10a-dodecahydro- } \\
\text { 4a,7-dimethyl-, [1R- } \\
(1 \alpha, 4 \mathrm{a} \beta, 4 \mathrm{~b} \alpha, 7 \beta, 10 \mathrm{a} \alpha)]-[\mathrm{C} 19 \mathrm{H} 28 \mathrm{O} 2]\end{array}$ & $\begin{array}{l}\text { Testosteron } \\
\text { (Kurnia Harlina, } \\
\text { 2000) }\end{array}$ \\
\hline 16.51 & 19.60 & $\begin{array}{l}\text { 1,2-Dihydro-11-oxo-prednisolone, 11- } \\
\text { dehydroxy-9-thiocynato- [C22H27NO5S] }\end{array}$ & Prednisolon \\
\hline
\end{tabular}

\section{PEMBAHASAN}

Salah satu upaya dalam pencarian tumbuhan yang berkhasiat obat tersebut dapat dilakukan dengan menggunakan cara

cilakukan

air yang selanjutnya dipisahkan dengan corong pisah. Minyak atsiri diteteskan sebanyak 1 tetes pada sepotong kertas saring dan didiamkan. Lalu diinjeksikan ke GC-MS yang dioperasikan menggunakan kolom kaca panjang $25 \mathrm{~mm}$, diameter 0,25 mm dan ketebalan 0,25 $\mu \mathrm{m}$ dengan fasa diam CP-Sil 5CB dengan temperatur oven di programkan antara $70-271^{\circ} \mathrm{C} /$ menit dengan kelajuan kenaikan temperatur $10^{\circ} \mathrm{C} /$ menit, gas pembawa Helium bertekanan $12 \mathrm{kPa}$, total laju 30 $\mathrm{ml} / \mathrm{menit}$ dan Split ratio sebesar 1: 50 (Mega, $\underline{2016)}$.
Spektrofotometer GC-MS. Spektrofotometri GC-MS berguna untuk mengidentifikasi zat-zat kimia beserta struktur molekul secara otomatis dan hasil yang didapatkan lebih akurat. Terdapat 
beberapa prinsip kerja yang dilakukan menggunakan alat GC-MS untuk mendapatkan zat-zat kimia, yaitu sample preparation, injeksi, GC separation, MS detector, dan scanning. Pada tahap proses injeksi, sampel yang telah dicairkan dengan etanol dan disaring akan diletakkan kedalam vial $2 \mathrm{ml}$. Proses penginjeksian akan berfungsi secara otomatis selama 3 menit dan suhunya akan meningkatkan dari $50-300^{\circ} \mathrm{C}$ dan akan kembali normal secara perlahan setelah proses penginjeksian selesai, pada tahap proses GC separation, campuran dibawa gas pembawa yaitu helium dengan laju alir tertentu melewati kolom GC yang telah panas. Pada tahap MS detector, senyawa dan molekul struktur di terindifikasi dengan referensi komputerisasi, pada tahap terakhir yaitu Scanning, hasil dari penginjeksian disimpan dalam sistem instrumen data untuk digunakan dalam analisis.

Hasil Kandungan Senyawa Kimia daun Nggorang (Salvia occidental Sw) menggunakan Spektrofotometer GC-MS adalah Terpenoida $\left[\mathrm{C}_{20} \mathrm{H}_{40} \mathrm{O}\right]$ sebagai Anti Bakteri (Yanuar, 2016) dan dapat menahan pembelahan sel sehingga dapat menghalangi pertumbuhan tumor (Harborne, 1986), Asam palmitat $\left[\mathrm{C}_{16} \mathrm{H}_{32} \mathrm{O}_{2}\right]$ berperan untuk mencegah penyakit kulit (Benade, 2003), Steroid $\left[\mathrm{C}_{20} \mathrm{H}_{30}\right]$ untuk mencegah penyakit kanker ovarium, prostat, payudara dan kanker usus besar dan mampu menghambat tiroid (Moon, 2017), Klorofil $\left[\mathrm{C}_{20} \mathrm{H}_{40} \mathrm{O}\right]$ untuk membantu mengoptimalkan fungsi metabolik, sistem imunitas, detoksifikasi, meredakan radang dan menyeimbangkan sistem hormonal (Madalena, 2007), Beta Karoten $\left[\mathrm{C}_{20} \mathrm{H}_{30} \mathrm{O}\right]$ dapat risiko penyakit jantung dan kanker (Kusbandari, 2017), Vitamin A $\left[\mathrm{C}_{20} \mathrm{H}_{32} \mathrm{O}\right]$ untuk mencegah penyakit mata (Benadé, 2003), Senyawa turunan Alkohol $\left[\mathrm{C}_{37} \mathrm{H}_{76} \mathrm{O}\right]$ dapat menurunkan kadar triglisida (Saputra, 2016), Asam Fenolik $\left[\mathrm{C}_{30} \mathrm{H}_{42} \mathrm{Cl}_{2} \mathrm{~N}_{4} \mathrm{O}_{3}\right]$ sebagai Antioksidan (Tristantini, 2016), Testosteron $\left[\mathrm{C}_{19} \mathrm{H}_{28} \mathrm{O}_{2}\right]$ berperan dalam menstimulasi terjadinya proses spermatogenesis (Guyton, 1995), Prednisolon $\left[\mathrm{C}_{22} \mathrm{H}_{27} \mathrm{NO}_{5} \mathrm{~S}\right]$ untuk mencegah pelepasan mediator dari dalam tubuh yang dapat menyebabkan inflamasi (Anjarwati, 2009).

\section{KESIMPULAN}

Berdasarkan hasil penelitian yang telah dilakukan dapat disimpulkan senyawa kimia dalam Daun Nggorang (Salvia occidentalis $S w$ ) terdiri dari senyawa Terpenoida, Asam Palmitat, Steroid, Klorofil, Vitamin A, Beta Karoten, Alkohol, Asam Fenolik, Testosteron dan Prednisolon

\section{SARAN}

Kepada peneliti selanjutnya disarankan dapat melakukan pengujian antioksidan menggunakan daun Nggorang (Salvia occidentalis $S w)$.

\section{DAFTAR PUSTAKA}

Anjarwati, A. 2009. Uji pendahuluan secara kualitatif adanya penambahan bahan kimia steroid dalam jamu antirematik. Skripsi. Universitas Indonesia

Benadé, A. J. S. 2003. A place for palm fruit oil to eliminate vitamin A deficiency. Asia Pacific Journal of Clinical Nutrition, 12(3), 369-372.

Harborne, J. 1986. Metode Fitokimia Edisi Kedua. ITB Bandung.

Kusbandari, A., \& Susanti, H. 2017. Kandungan Beta Karoten dan Aktivitas Penangkapan Radikal Bebas Terhadap DPPH (1,1difenil 2-pikrihydrazil) Ekstrak Buah Blewah (Cucumis melo var. cantalupensis L) Secara Spektrofotometri UV-Visibel. Journal of Pharmaceutical Sciences and Community, 14(1), 37-42. https://doi.org/10.24071/jpsc.141562

Madalena, M., Heriyanto, H., Hastuti, S. P., \& Limantara, L. 2007. The Effect Of Heating Time To The Content Of Pigments And Vitamin A In Cassava Manihot esculenta Crantz) And Ceara-Rubber (Manihot glaziovii Muell. Arg) Leaves. Indonesian Journal of Chemistry, 7(1), 105-110. https://doi.org/10.22146/ijc.21722

Mega Rizky Novitasari, Lizma Febrina, Risna Agustina, Agung Rahmadani, dan R. R. 2016. Analisis GC-MS Senyawa Aktif Antioksidan Fraksi Etil Asetat Daun Libo (Ficus variegata Blume.). Journal of Chemical Information and Modeling. https://doi.org/10.1017/CBO97811074153 24.004

Moon, C. L., Oleo, U. H., Tenggara, S., Farmasi, F., \& Gadjah, U. 2017. Isolasi Senyawa Steroid dari Kukit Akar Senggugu. Pharmacon.Vol.6.No3. https://doi.org/10.35799/pha.6.2017.1711 9

Saputra, F. 2016. Uji Efek Ekstrak Etanol 96\% Anggur Merah (Vitis vinifera) Terhadap Penurunan Kadar Trigliserida Pada Tikus Putih (Rattus Novergicus) Yang Diberi Pakan Hiperkolesterolemia dan Diinduksi 
Triton X-100. Journal of Chemical Information and Modeling, 53(9), 16891699.https://doi.org/10.1017/CBO978110 7415324.004

Tristantini, D., Ismawati, A., Pradana, B. T., \& Gabriel, J. 2016. Pengujian Aktivitas Antioksidan Menggunakan Metode DPPH pada Daun Tanjung ( Mimusops elengi L ).

Skripsi Universitas Indonesia.

Wati, M., Erwin, \& Tarigan, D. 2017. Isolasi dan Identifikasi Senyawa MetabolitSekunder dari Fraksi Etil Asetat pada Daun Berwarna Merah Pucuk Merah (Syzygium myrtifilium Walp.).Skripsi Kimia FMIPA Unmul, 14(2), 100-107.

\footnotetext{
(c) (i) ()
} 